This report was prepared as an account of work sponsored by an agency of the United States Government. Neither the United States Government nor any agency thereof, nor any of their employees, makes any warranty, express or implied, or assumes any legal liability or responsibility for the accuracy, completeness, or usefulness of any information, apparatus, product, or process disclosed, or represents that its use would not infringe privately owned rights. Reference herein to any specific commercial product, process, or service by trade name, trademark, manufacturer, or otherwise does not necessarily constitute or imply its endorsement, recommendation, or favoring by the United States Government or any agency thereof. The views and opinions of authors expressed herein do not necessarily state or reflect those of the United States Government or any agency thereof.

SAND- $-92-2085 C$

DE93 002300

\title{
EFFLUENT TREATMENT OPTIONS FOR NUCLEAR THERMAL PROPULSION SYSTEM GROUND TESTS
}

Larry R. Shipers

Sandia National Laboratories

P. O. Box $5800 / 6513$

Albuquerque, New Mexico 87185

(505)845-7016

Prepared for:

Tenth Symposium

on Space Nuclear Power and Propulsion Session: 27. NTP: Facilities and Testing I Albuquerque, New Mexico

January 10-14, 1993

Initial Submission: 04 Sept 1992

Final Submission: 16 Oct 1992

\author{
John E. Brockmann \\ Sandia National Laboratories \\ P. O. Box 5800/6422 \\ Albuquerque, New Mexico 87185 \\ (505)845-3201
}




\section{DISCLAIMER}

This report was prepared as an account of work sponsored by an agency of the United States Government. Neither the United States Government nor any agency Thereof, nor any of their employees, makes any warranty, express or implied, or assumes any legal liability or responsibility for the accuracy, completeness, or usefulness of any information, apparatus, product, or process disclosed, or represents that its use would not infringe privately owned rights. Reference herein to any specific commercial product, process, or service by trade name, trademark, manufacturer, or otherwise does not necessarily constitute or imply its endorsement, recommendation, or favoring by the United States Government or any agency thereof. The views and opinions of authors expressed herein do not necessarily state or reflect those of the United States Government or any agency thereof. 


\section{DISCLAIMER}

Portions of this document may be illegible in electronic image products. Images are produced from the best available original document. 


\title{
EFFLUENT TREATMENT OPTIONS FOR NUCLEAR THERMAL PROPULSION SYSTEM GROUND TESTS
}

\author{
Larry R. Shipers \\ Sandia National Laboratories \\ P. O. Box 5800/6513 \\ Albuquerque, NM 87185 \\ (505) 845-7016
}

\author{
John E. Brockmann \\ Sandia National Laboratories \\ P. O. Box 5800/6422 \\ Albuquerque, NM 87185 \\ (505) 845-3201
}

Keywords: Nuclear Thermal Propulsion, Ground Testing, Effiuent Treatment

\begin{abstract}
Abstráct
A variety of approaches for handling effluent from nuclear thermal propulsion system ground tests in an environmentally acceptable manner are discussed. The functional requirements of effluent treatment are defined and concept options are presented within the framework of these requirements. System concepts differ primarily in the choice of fission-product retention and waste handling concepts. The concept options considered range from closed cycle (venting the exhaust to a closed volume or recirculating the hydrogen in a closed loop) to open cycle (real time processing and venting of the effluent). This paper reviews the strengths and weaknesses of different methods to handle effluent from nuclear thermal propulsion system ground tests.
\end{abstract}

\section{INTRODUCTION}

Testing of fuel, fuel elements, and engine assemblies at a suitable facility is required to support the development of nuclear thermal propuision (NTP) systems. The NERVA/ROVER program, conducted in the 1960s and early 1970s, was the only NTP ground test program conducted in the USA. With the exception of the last tests performed in the NERVA/ROVER program, all of the ground tests vented the reactor exhaust through a convergent-divergent nozzle directly to the atmosphere (Koenig 1986). Given the current Environmental Safety and Health (ES\&H) regulations, policies, and guidelines in the USA, it is not planned today to vent potentially contaminated hydrogen directly to the atmosphere. A system to treat the reactor exhaust prior to release to the atmosphere was incorporated into the design of the Nuclear Furnace-1 (Kirk 1973) which was the last test stand constructed as a part of the NERVA/ROVER program. This system demonstrated the capability of removing fission products from a reactor exhaust stream. While this experience is encouraging, it is necessary today to reduce the potential releases of fission products and other contaminants to the environment to as low as reasonably achievable (ALARA).

In order to minimize the potential safety and environmental impacts of NTP ground tests, the gaseous reactor effluent needs to be confined, treated, and/or scrubbed of radioactive fission products prior to its unrestricted release. Over the years, several different options have been evaluated by Sandia National Laboratories to either process the hot hydrogen effluent simultaneously with the test being conducted or configure the test facility in a manner that real time processing is not required. The evaluation effort was initiated by identification and formulation of a wide range of concept options to treat NTP test article exhaust. The concept options considered ranged from closed cycle (venting the exhaust to a closed volume or recirculating the hydrogen in a closed loop) to open cycle (real time processing and venting of the effluent). A number of variations of these general concepts are still under consideration. This paper reviews the strengths and weaknesses of different methods to handle effluent from nuclear thermal propulsion system ground tests. 


\section{SYSTEM FUNCTIONS}

A number of solid core reactor concepts are under consideration for development for NTP systems (Clark et al. 1992). Prismatic (NERVA Derived), particle (PBR and Pellet bed), and refractory (Cermet, Wire Core) fuel forms are all candidates for ground testing as a part of a NTP development program. Consideration of these varied concepts leads to a consistent set of functional requirements for any system designed to treat the reactor exhaust during ground testing. In all cases, fuel operating temperatures in the range of 2700 to $3400 \mathrm{~K}$ are planned.

Cryogenic hydrogen is the propellent of choice for these concepts because of its low molecular weight. Significant quantities of cryogenic hydrogen will be required to cool NTP reactors tested under prototypic conditions. At a mixed mean outlet temperature of $3000 \mathrm{~K}$, a liquid hydrogen coolant flow rate of $0.02 \mathrm{~kg} / \mathrm{s}$ is required for each megawatt of power generated. Even small fuel element test reactors with powers on the order of $50 \mathrm{MW}$ would require $1 \mathrm{~kg} / \mathrm{s}$ coolant flows. Ground testing of reactors with powers as high as $2000 \mathrm{MW}$ have been proposed (Allen et al. 1992). These reactors would require coolant flows in the range of $40 \mathrm{~kg} / \mathrm{s}$.

As the hydrogen coolant flows through a fuel element and is heated by direct contact with the nuclear fuel, it is anticipated that it will become contaminated with fission products and/or fuel particulate. The potential for the generation of other hazardous compounds within the hydrogen also exists. The risk of significant contamination is especially high early in the development process when new and advanced fuel forms are expected to be tested. Available data for release rates associated with advanced fuel forms and coatings, especially at the anticipated elevated temperatures, is limited. Testing at the end of the NERVA/ROVER program did indicate significant fuel element cracking and fission-product and noble gas releases from matrix fuel operated at a mixed mean coolant outlet temperature of $2440 \mathrm{~K}$ (Kirk 1973).

The reactor exhaust can also be expected to contain significant quantities of core material and debris. Early in the NERVA/ROVER program ground tests of matrix type fuel forms were observed to have failures which resulted in significant core material being ejected from the reactor nozzles (Finseth 1991). While the NERVA/ROVER program eventually solved the flow instability problems that caused the reactor core failures, this experience demonstrates the need to allow for the potential of significant core failure and relocation during the development of any NTP concept.

Solid core NTP ground test reactors would generate from one to tens of kilograms per second of very high temperature (in excess of $3000 \mathrm{~K}$ ) hydrogen. The hot hydrogen can be expected, at a minimum, to be contaminated with low concentrations of small particulate, fission products, volatile species, halogens, and noble gases. In addition, it is likely that significant core material and debris will be entrained in the exhaust during the initial fuel and fuel element development program.

Any system designed to treat the exhaust from a solid core NTP ground test reactor must perform four basic functions (see Figure 1):

1. Initial cooling of the hot reactor exhaust to temperatures compatible with normal engineering materials. In addition, any debris and large particulate ejected from the core must be retained and maintained in a subcritical configuration.

2. Intermediate cooling to temperatures at or below atmospheric. While this cooling stage is not necessary, its inclusion in the system enhances the performance of many concepts.

3. Fission-product retention to prevent uncontrolled release of contaminants to the environment. This stage must be designed to retain small particulate, halogens, noble gases, and other volatile species.

4. Waste stream processing to properly handle retained fission products, cleaned or processed hydrogen effluent, and any other potentially contaminated fluids introduced in or generated by the system.

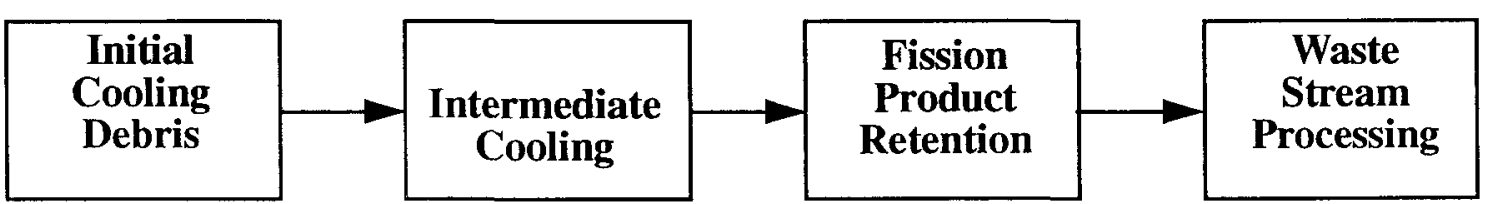

FIGURE 1. NTP Solid Core Reactor Effluent Treatment Functions. 
The collection of components that performs these functions is normally referred to as an effuent treatment system (ETS).

\section{CONCEPT OPTIONS}

A number of concepts have been proposed to perform the functions of exhaust treatment for solid core NTP ground test reactors (Kirk 1973, Bohl et al. 1990, Whitbeck and Olsen 1991, Clark 1992, and Harmon et al. 1992). ETS concepts can be grouped into three broad categories: closed volume systems, open systems, and closed loop systems. Closed volume systems delay and accumulate the effluent generated during reactor power operations and then process the effluent at much reduced flow rates at some time after power operations. Closed volume systems include concept options such as venting the effluent to storage vessels or metal hydrides. In an open system, the effluent is processed and vented to the atmosphere as it is produced during reactor power operations. Open systems are characterized by large capacity filtration and adsorption equipment. A closed loop system performs real time processing of the effluent and then recirculates the hydrogen to the reactor inlet to be reused as coolant. Care must be used when comparing a closed loop system to other types of ETS concepts. The closed loop system both treats the reactor exhaust and performs the additional function of supplying coolant to the reactor inlet. The appropriate functional relationship is maintained when a closed loop system is compared to another ETS concept in combination with the concept and components used to supply coolant to the test reactor.

The commonalities of ETS component options and the impacts of component choices are illustrated in Figure 2. Tracing any single path through this figure will define a complete effluent treatment system. Each of the three categories (closed volume, open, closed loop) of effluent treatment concepts have the same options for components to perform the initial cooling, debris retention, and intermediate cooling functions. The concepts differ in the components used for fission-product retention and waste-stream processing. The choice of the method used for initial cooling can also influence the components that must included in the intermediate cooling, fission-product retention, and waste processing stages.

\section{Debris Retention Options}

There are three options to satisfy the debris retention function: (1) a curved duct with a sump or trap; (2) a large vessel with a coarse filter at the exit; and (3) a cyclone separator. These components would remove debris and large particulate by turning and slowing the flow. As the flow is slowed to subsonic conditions, the temperature of the effluent can be expected to approach that of the reactor exhaust $(-3000 \mathrm{~K})$. Thus these components must be insulated and/or actively cooled to survive. Refractory, ceramic, or ablative linings are options for insulators. Any lining would be subjected to the potential of serious damage from debris impacts. Ablative linings would introduce significant additional particulate into the effluent stream, increasing the potential for fouling and plugging of downstream components. The debris retention components could be actively cooled using jackets or tubes with liquid hydrogen, liquid nitrogen, or water flowing through them. A jacketed water-cooled curved duct was successfully used during the NERVA/ROVER program to turn the exhaust of a NTP engine (Aerojet 1969). Water-cooled diffusers are used in high altitude rocket engine test stands. However, the coolant flow rates required in these components can be quite high. For example, the NERVA/ROVER duct was designed to flow $66 \mathrm{~kg}(1050 \mathrm{gal})$ of water for each kilogram of nozzle fiow. This implies a water flow rate of $1.3 \mathrm{~kg} / \mathrm{s}(21 \mathrm{gpm})$ for each megawatt of power generated by the test reactor. Cooling design of the curved duct and cyclone options is especially critical since in these geometries it must be assumed that the hot jet will impinge on the pressure boundaries of the component. It is possible to size a large vessel so that no impingement will occur. This is an important consideration because a failure of the ETS at this location would bypass the entire system function and have the potential for significant environmental consequences.

Any of the three debris retention components considered could incorporate a coarse filter at or near its exit. The function of this coarse filter would be to enhance debris retention capability, to retain large particulate to reduce the potential for fouling and plugging of downstream components, and (if properly designed) to provide a thermal mass for plate out of volatile species with boiling points below the debris trap operating temperature. In order to avoid the potential for overpressure and breech of the debris trap, this coarse filter would be required to be designed in a manner that either would not allow plugging or would allow pressure relief.

The debris retention component must also be designed in a manner that allows survival and recovery from a significant core failure and relocation. If the component functions as desired, the majority of the core debris and material resulting from a significant failure would be retained. While the debris trap must be designed to maintain this material in a subcritical configuration, it is unlikely that it would be acceptable to allow this fissionable debris to 
remain in the debris trap for multiple operations. Thus the design must allow for removal of the majority of the failed core material (probably by remote or robotic means).

\section{Cooling Options}

Active cooling of the debris trap can be expected to result in some limited cooling of the effluent stream. However, the bulk of the cooling required to lower the effluent temperature to a range compatible with normal engineering materials must be performed by other components. Three options exist to perform this function: (1) direct cooling by injection and mixing, (2) heat removal by a heat exchanger, and (3) heat storage in a pebble bed heat sink.

The heat exchanger and pebble bed options would have the potential for the same high heat fluxes as the debris trap and thus would have many of the same critical cooling design concerns. In addition, these two cooling components would be required to be located downstream of the debris retention component to avoid fouling and plugging. Coolant injectors could be located at or near the entrance of the debris trap. This injection geometry has the advantage of lowering the effluent mixed mean temperature (and the debris trap operating temperature) and relaxing the critical cooling design requirements for the debris trap. It also allows the debris trap jacket cooling and the injection cooling to serve as potential redundant systems. Given a failure of either system, the other has the potential to cool the debris trap sufficiently to maintain its structural integrity. However, this potential redundancy is not attained if the flow circuit is constructed so that coolant flows through the debris trap jacket or tubes and then is injected into the effluent stream. Injection cooling has the additional potential advantage of being designed as an injector or ejector (Pope and Goin 1965). This could lower the ETS backpressure and allow integral supersonic nozzle testing during the reactor development program.

\section{Heat Exchangers}

A large number of heat exchanger design options are available. They include boilers, tube and shell, finned tube, and finned plate as well as more exotic designs. The major design considerations in heat exchanger selection are related to the robustness of the component. The heat exchanger will experience significant thermal cycling (rather than long-term, steady-state operation) over temperatures ranging from as low as cryogenic (potentially encountered during reactor startup). The potential for significant plate out of fission-products within the heat exchanger will make maintenance difficult and costly. Thus low maintenance designs that have a strong resistance to fouling, plugging, and leaks should be considered.

Liquid hydrogen, liquid nitrogen, and water are all candidates for use as coolants in beat exchangers. Because of its lower storage temperature and higher heat capacity, the required liquid hydrogen volumetric cooling flow is about $75 \%$ of that required by liquid nitrogen. Steam generators require even lower volumetric flow rates. However, systems using water as a coolant can be expected to be more complicated than those using other fluids. Hydrogen (after flaring) and nitrogen heat exchanger coolant can be vented to the atmosphere. However, water heat exchangers (with the exception of steam generators) require, at a minimum, a hot coolant holding tank and a means to reject the stored heat between reactor power operations. Increasingly complex water coolant support systems, such as using ice or refrigeration to pre- or postcool the water, can be developed. Heat exchanger coolant recirculation systems using cooling towers, air-to-water heat exchangers, and/or secondary cooling loops may also be used. In all cases, the number of system components and the operational complexity of a water coolant system can be expected to increase.

\section{Pebble Bed Heat Sinks}

Use of a pebble bed heat sink presents some unique design considerations. First, the temperatures over some portion of the bed would approach those of the effluent $(\sim 3000 \mathrm{~K})$. This limits the choice of bed materials to ceramics and refractories. The ability of these materials to survive the repeated thermal cycling from cryogenic to very high temperatures would require verification. The shell of the heat sink would have to be actively cooled in order to allow its construction from normal engineering materials. In addition, a heat removal system to cool the pebble bed between reactor power operations would be required. Because of the potential for an extended time period between power operations, the load on this off-line heat removal system could be significantly less than required for a real time system. However, the need for this support system and its potential impacts on operations during reactor decay energy removal after power operations should not be overlooked. The pebble bed can be expected to become highly contaminated as it provides as ideal medium for plate out of volatile species. A pebble bed also has a defined energy adsorption limit so that other cooling concepts may offer more flexibility for future expansion. 


\section{Injection Cooling}

Liquid hydrogen, liquid nitrogen, and water may all be used as injection coolants. As with heat exchangers, liquid hydrogen coolant volumetric flow rates can also be expected to be lower than those required for liquid nitrogen injection. Nitrogen injected into the effluent stream can also be expected to react with the hydrogen to produce ammonia. If any carbon exists in the effluent (which is likely under fuel failure conditions), the injected nitrogen could react and produce cyanogens. While introducing these contaminants into the effluent stream does not cause insurmountable difficulties, it does increase the required complexity of the liquid and gaseous waste processing systems. Introducing large quantities of nitrogen into the effluent stream has the potential to significantly complicate the fission-product retention stage of many of the ETS options. Nitrogen removal or special nitrogen handling systems would be required for successful operation of this stage in many of the concept options. Thus liquid nitrogen is considered the least desirable of the injection coolants.

Water is an attractive choice for injection cooling because of its high heat of vaporization. In addition, water droplets in the effluent stream can act as an effective scrubber removing a significant portion of the fission products, iodine, and small particulate. However, introduction of water into the ETS does introduce some design complications. Chemical reactions of water in the effluent stream can lead to significant energy releases that must be considered during the ETS design. For example, energy releases of $4.6 \mathrm{MJ} / \mathrm{kg}$ have been observed for molten aluminum and water reactions (Rightley and Beck 1992). Other potential chemical reactions are water with beryllium, uranium carbide, or zirconium carbide.

Several of the fission product retention concepts require that the injected water be removed from the stream prior entering the retention stage (see Figure 2). Water can be a significant poison for both hydride beds and charcoal adsorbers. Water freezing during a hydrogen liquefaction process could, depending upon the location, have serious implications. At a minimum, the ice would act as debris and particulate in the liquefaction process train. Injected water can be removed from the effluent by a combination of steam generators, condensers, separators, and desiccant dryers (as demonstrated by NF-1). The load on the water removal component will be high, since the injection process does not remove any energy from the effluent stream. It simply stores the energy in the steam entrained in the effluent. The stored energy must be removed from the effluent stream in order to condense and remove the water. The removal process does require significant additional components and complexity that are not required for hydrogen or nitrogen injection. The potential to generate large quantities of contaminated liquids is a serious concern for water injection systems. All water removed from the effluent stream must be assumed to be contaminated. This potentially contaminated water must be temporarily stored and handled as liquid waste until the contaminants have been removed or it has been demonstrated that no contaminants exist. The systems to handle this contaminated water will be more complex and costly than normal water handling equipment. The use of liquid hydrogen and liquid nitrogen for cooling avoids the complications of water systems at the penalty of an increased coolant cost for test operations. However, the life cycle increased coolant costs must be balanced against the increased capital costs and operating complexity of water cooled systems.

Two additional considerations must be included in the design and selection of ETS cooling concepts. First, all cooling components (including supply vessels and systems, holding tanks, heat exchangers, and jackets) must be designed to operate at a pressure above that in the effluent stream. Thus if a leak occurs, coolant will be vented into the effluent stream rather than the leak providing a path for contaminated effluent to bypass the fission-product retention stage. This consideration is especially critical for components, such as heat exchangers, which are prone to small leaks. Second, systems that supply coolant to the ETS must be evaluated from a safety as well as a functional viewpoint. Initial cooling of the effluent is critical to the successful operation of any ETS concept and the supporting coolant supply systems should have the appropriate level of redundancy and reliability. In general passive blowdown supply systems are considered to be less prone to failure than active pumped systems. Common mode failures must be avoided. Redundant supply lines, pumps (if used), and pump power sources should be considered.

The intermediate cooling options, with one addition, are the same as those discussed for initial cooling. Because of the lower anticipated operating temperature in this stage, it should be possible to use a water spray for direct contact cooling. This option retains both the advantages and disadvantages of introducing water into the effluent stream. The lower operating temperature also eliminates the high temperature design concerns associated with heat exchangers and pebble bed heat sinks. Other cooling design considerations for this stage remain the same as previously discussed. 


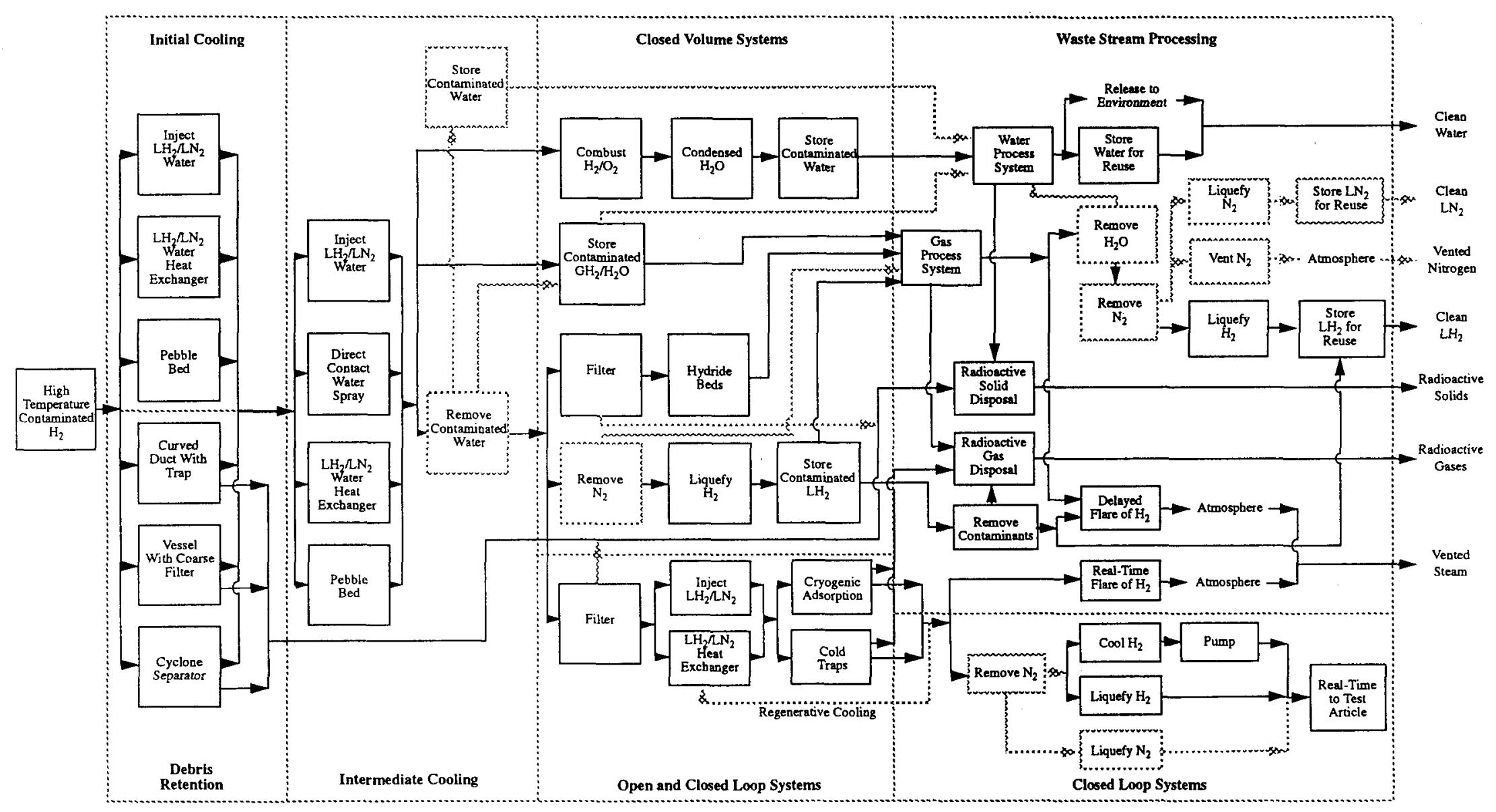

FIGURE 2. NTP Solid Core Reactor Effluent Treatment Options 


\section{Closed Volume Options}

Closed volume options include venting the gaseous effluent to storage vessels, venting to metal hydrides, condensing the hydrogen effluent to a liquid (smaller volume) for potential reuse as coolant, and combusting the hydrogen to form steam and condensing to water (see Figure 2). All of these concepts collect the contaminated hydrogen during test operations and retain the contaminants for posttest decay, treatment, and disposal. The concepts differ in the real time processing options that may be performed in order to reduce the volume of the effluent prior to storage. The simplest concept is to vent the cooled effluent to storage vessels. The effective hydrogen storage capacity is strongly dependent on the storage temperature and pressure selected. Assuming a storage pressure of 1.4 $\mathrm{MPa}$ (a reasonable upper limit for a reactor operating at a $6.9 \mathrm{MPa}$ chamber pressure) at ambient temperature yields a hydrogen storage capacity of $1.1 \mathrm{~kg} / \mathrm{m}^{3}$ of storage volume. The storage density can be significantly increased (at the penalty of the added complexity of pumping the effluent) by increasing the storage pressure. The total storage volume required can be strongly effected if injection cooling is used in the upstream components.

The required storage volume can be greatly reduced by liquefying the hydrogen prior to storage. Effective storage densities approaching $70 \mathrm{~kg} / \mathrm{m}^{3}$ can be obtained. However, real time liquefaction of the hydrogen effluent greatly complicates the ETS. The need to remove any injected water has been previously discussed. It would also be necessary to remove any injected nitrogen from the effluent stream because the nitrogen freezing point is above the hydrogen boiling point. This could be accomplished using a cascade liquefaction process, which would also allow the liquid nitrogen to be recovered. The energy requirements to liquefy the hydrogen are quite high. The ideal work requirements for liquefying hydrogen initially at standard conditions is $11.6 \mathrm{MJ} / \mathrm{kg}$ of liquid produced (Timmerhaus and Flynn 1989). Thus a minimum power equal to approximately $23 \%$ of the power generated by the ground test reactor would be required just to liquefy the reactor hydrogen coolant. Actual liquefaction power requirements can significantly exceed the ideal values presented here.

Venting the effluent to metal hydride beds has the potential to approach the effective hydrogen storage densities of liquefaction systems. Granular iron titanium hydride beds have demonstrated on a pilot plant scale an effective storage density of $48 \mathrm{~kg} \mathrm{H}_{2} / \mathrm{m}^{3}$ of bed volume (Salzano 1974). The ability of iron titanium hydride beds to effectively store hydrogen is strongly dependent upon the bed operating temperature and pressure. The effective storage capacity of the hydride bed is increased by either decreasing temperature and/or increasing pressure. Temperatures below 330 $\mathrm{K}$ are required for effective storage in iron titanium hydride at pressures in the range of 1.2 MPa (Lin and Watson 1987). Consideration of finite hydriding rates can require bed volumes significantly larger than ideal equilibrium calculations predict in order to avoid large pressure buildups in the beds.

Bed granule size, heat removal efficiency, and impurities can have significant impacts on hydriding absorption rates. Studies at Sandia National Laboratories indicate that hydriding metal powders must have a large specific surface area to induce rapid adsorption (Baer 1991). Bed particle sizes of $500 \mathrm{~mm}$ or smaller may be required. Thus an effective full capacity effluent filtration system is required upstream of the hydride bed to prevent bed plugging and fouling (see Figure 2). This filtration system can be expected to be very similar in design to that required for a open system. It is necessary to remove energy from the hydride bed of approximately $13.5 \mathrm{~kJ} / \mathrm{kg}$ of hydrogen adsorbed. If this energy is not efficiently removed, hot spots will occur in the bed that slow or limit the hydriding process. The introduction of trace species (such as carbon monoxide, water, and oxygen) has been observed to significantly reduce the hydriding rates. Rate reductions from poisons as high as an order of magnitude have been reported (INCO 1980). Thus it is necessary to both isolate the hydride system from the atmosphere and to limit the concentrations of oxygen containing contaminants in the effluent stream. Any injected water coolant would be require removal to very low concentrations with a high reliability. The impacts of nitrogen injection on the beds is unknown. However, at a minimum, a sufficient storage volume in the hydride system for the free nitrogen gas would be required. Use of liquid hydrogen injection cooling would significantly increase the required size of the hydride bed.

The combustion concept would inject liquid oxygen into the effluent stream, combust the mixture, and remove sufficient heat to condense the resulting combustion products (primarily steam). Complete combustion would require $8 \mathrm{~kg}$ ( 2 gal liquid) of oxygen for each kilogram of hydrogen. Assuming the resulting water was stored at standard conditions, the effective hydrogen effluent storage density would be approximately $100 \mathrm{~kg} \mathrm{H}_{2} / \mathrm{m}^{3}$ of water storage. Thus the combustion process offers the potential for the most efficient hydrogen storage. This concept does, however, have all of the previously discussed potential disadvantages associated with injecting water into the effluent stream. In addition, this concept places significant additional energy loads on the ETS. The combustion process would release energy in the range of $120-140 \mathrm{MJ} / \mathrm{kg}$ of hydrogen burned. This yields a power generation in excess of 2.5 times that generated by the test reactor. In order to condense the resulting steam, it would be necessary to remove additional 
energy. Options to remove this energy do exist (as previously discussed), but the required systems would be large, complicated, and expensive. Designing a system that would reliably ensure complete combustion at the anticipated effluent flow rates may be a challenge. The combustion design would be further complicated (because of the potential for inerting) if nitrogen or water injection cooling was performed in the upstream stages of the ETS.

The fact that all of these systems place the effluent in a limited closed volume during test operation causes several addition design concerns. As the power operation is performed, the pressure in these systems will build to some level above atmospheric. As the power operation is terminated and coolant flow is stopped, this pressure will remain at an elevated level (unlike an open system) and the potential exists for backflow through the test article. Thus some isolation mechanism will be required to be activated during the reactor shutdown process. While this consideration is especially serious for the gas storage and hydride bed options, it will also be necessary to vent the overpressure from the liquid storage options. Leaks while the components are held at elevated pressures have the potential to release fission products to the environment. The hydride and combustion storage system have the potential to release the fission products (especially the noble gases) at concentrations above that of the original reactor exhaust. Operation during reactor decay energy removal must also be considered. Either storage allowances in the component design must be made for decay heat removal fluids (with the potential for operation at the elevated storage pressure during decay energy removal) or an alternate system (potentially an open system) must be incorporated into the design to handle the decay heat fluids.

The closed volume concepts must include systems with sufficient capacity to process and dispose of the retained waste between reactor power operations. However, these treatment systems may be smaller than those required for the real-time processing options because of the longer time duration available for treatment. The required systems fall into two categories: (1) systems to manage the hydrogen effluent and injected coolant fluids (if any) and (2) systems to collect and properly dispose of fission products (see Figure 2). Fission product removal systems for both liquid and gaseous effluents may be required. If the combustion and condensation concept or any injected water cooling is performed, a water treatment system would be required. This processing can be expected to include filtration stages for particulate removal as well as stages designed to remove iodine and other soluble gases. Demineralization would also be required for any water that was planned to be reused. The treated water could either be stored for reuse or released to the environment.

All of the closed volume systems would require a gaseous effluent process system. The hydrogen in the gaseous storage and hydride bed options would be required to be removed from storage and processed between operations. A system to heat the hydride beds would be required to promote effective hydrogen off-gassing. The contaminated boiloff from the hydrogen liquefaction and storage concept would require treatment prior to venting to the atmosphere. It is unlikely that it would be acceptable to vent even the contaminated water storage directly to the atmosphere without treatment. The gaseous effluent process train can be expected to contain equipment for removal of particulate, halogens, noble gases, and other volatile species. This system would be expected to have the same type of equipment (on a smaller scale) as would be required for a real time processing open system. After processing, the hydrogen could be either flared and vented to the atmosphere or liquefied and stored for future use. Any injected water or nitrogen would be required to be removed (as previously discussed) prior to liquefaction. Concentrations of injected water and nitrogen would effect the flare system design but this is not an insurmountable obstacle.

The contaminated liquefied hydrogen effluent would, at a minimum, require filtration to remove entrained particulate and any solidified contaminants. An adsorption stage may also be required. The processed hydrogen could then either be stored for future use or flared and vented to the atmosphere.

\section{Open System Options}

An open loop system must have components with sufficient capacity to remove small particulate, halogens, noble gases, and other volatile species from the effluent at the reactor full power flow rates. The removal functions can be grouped into two categories: (1) solid (particulate) removal and (2) gaseous and vapor phase removal. Design of particulate removal systems is complicated by the fact that the particle size distribution is unknown. Systems must be designed to effectively remove particulate at the most penetrating size $(\sim 0.3 \mu \mathrm{m})$ making filtration design optimization difficult. Robustness in both mechanical design and removal efficiency are important considerations in the selection and design of filtration systems. A wide range of failure modes can be postulated for the test reactors during development testing. Many of these failures have the potential to generate a temperature and/or pressure pulse that would propagate through the ETS. Any filtration system must be designed to maintain its efficiency and function under these potentially adverse operating conditions. The ETS can also be expected to operate over a wide range of 
reactor power levels. The filtration system must maintain its efficiency over a potentially wide range of effluent flow rates and operating pressures. Filtration systems for an ETS have the potential to deviate from normal industrial practice in two major ways. In industrial systems pressure drop translates directly to power consumption so that minimum pressure drop designs are required. Also, most industrial systems operate at pressures just slightly above atmospheric. Depending upon operating and allowable backpressure, an ETS may have very different requirements.

Particulate may be removed by either wet (scrubbing) systems or dry filtration. Wet systems include submerged gravel bed scrubbing, venturi scrubbing and demisting, and injection scrubbing. These systems can effectively remove iodine as well as particulate. The NF-1 demonstrated that water injection cooling was an effective means to remove a wide range of fission products from a hydrogen exhaust stream (Kirk 1973). The submerged gravel bed when used in conjunction with fibrous demisters has been demonstrated to be an effective filtration system (McCormack et al. 1984). However, these designs can become quite large because of the low maximum superficial gas velocity and large water volume requirements. Venturi scrubbers and demisters are widely used in power plant, incinerators, and industrial processes. A system with an adjustable throat design to allow for varying operating conditions would be required for ETS applications. All of these systems do, however, have the disadvantage of introducing large quantities of water into the effluent stream. Since the downstream components are required to operate at cryogenic temperatures, any water introduced into the stream would require removal. The complications associated with water removal have been previously discussed.

Options for dry filtration include fabric fiber, glass fiber HEPA, metal fiber, sintered metal, and granular media filters. All of these filter types can be designed for high removal efficiencies over a wide range of particle sizes. Fabric fiber (baghouse) and glass fiber HEPA filters are normally designed to operate at pressures slightly above atmospheric and to survive a few tens of $\mathrm{kPa}$ (a few psi) of pressure drop. Baghouse designs can also be quite large. The potential blowout risks associated with both fabric and glass fiber filters bring their utility for this effluent treatment application into question. All three of the remaining filter concepts have the potential to satisfy the ETS needs for a robust design. In general, granular media filters can be expected to be more cost effective than either metal fiber or sintered metal filters.

Various adsorption processes to remove gaseous and vapor phase contaminants are possible. Iodine can be effectively removed using activated charcoal at ambient temperature. However, operation at cryogenic temperatures is necessary to remove noble gases from the effluent stream. The effluent can be cooled to cryogenic temperatures by injection mixing and/or heat exchangers. Both liquid hydrogen and liquid nitrogen are candidates for the cooling fluid. Direct cooling by injection would require lower coolant flow rates than heat exchangers at the penalty of requiring additional downstream process capacity. Because heat exchanger coolant is not introduced into the effluent stream, additional systems to flare or vent this coolant would be required. A regenerative concept using the effluent downstream of the cryogenic adsorption stage to precool the effluent upstream of liquid hydrogen injection (see Figure 2) was used in the NF-1. While this concept does make effective use of the cooling capacity of the system effluent, it was a major shortcoming that may not be acceptable today. Unless the downstream effluent is pumped, the regenerative heat exchanger cold side would operate at a pressure below that of the effluent stream. Thus a heat exchanger leak would provide a path for contaminants to bypass the gas and vapor phase removal stage of the ETS and reach the environment.

Cold traps have been suggested as an option for xenon and krypton removal. The concentrations of these contaminants in the effluent stream is expected to be very low (potentially on the order of several parts per million). Even at such low concentrations these contaminants have the potential to produce a significant dose and cannot be vented directly to the environment. The low concentrations lead to partial pressures that may approach the saturation pressures over solids. At these concentrations, it would be difficult if not impossible to remove the xenon and krypton using cold traps.

Cryogenic adsorption can effectively remove the noble gases even when they exist at very low concentrations. Both silver mordenite and activated charcoal have been proposed as adsorption media. The NF-1 demonstrated that cryogenic charcoal adsorption could effectively remove krypton from a hydrogen effluent stream (Kirk 1973). A key parameter in adsorption bed design is the holdup time of krypton. The dynamic adsorption coefficient for krypton is at least an order of magnitude smaller than that for xenon. Iodine is more readily adsorbed than xenon. Thus, any adsorption bed designed to effectively remove krypton should remove xenon, iodine, and other vapor phase contaminants at a removal efficiency higher than that for krypton. However, the design must ensure that sufficient bed volume exists to retain all of the expected contaminants. 
Open cycle concepts must have systems to manage two operational waste streams: (1) the hydrogen effluent and (2) the contaminated noble gases retained in the cryogenic adsorption beds. Once the contaminants have been removed from the effluent stream, the remaining hydrogen can be flared and vented to the atmosphere. Any injected water would have been removed by upstream components. Any injected nitrogen, while it would effect the flare system design, could be vented with the hydrogen. The cryogenic adsorption beds provide only a temporary retention capacity for the noble gases. It will be necessary to regenerate the beds between reactor power operations. If the adsorption beds are allowed to warm to above cryogenic temperatures the xenon and krypton will off-gas. Two options exist to manage the noble gases. One possibility is to isolate the cryogenic adsorption beds (either individually or as a unit), allow the beds to warm, and collect the off-gases in a cryopump for appropriate handling and disposal. A second alternative is to isolate the adsorption beds for a sufficient period to allow for the decay of the radioactive gases to an acceptable level and then to vent them in a controlled manner to the atmosphere. Any adsorbed iodine can be expected to remain in the charcoal beds unless they are heated to the range of $400 \mathrm{~K}$, but it will also decay.

\section{Closed Loop Option}

The closed loop system is a logical extension of an open system (see Figure 2). In this system, the exhaust of the cryogenic adsorption stage is cooled to temperatures approaching that of liquid hydrogen and supplied to the reactor inlet to be used as coolant. Because it is expected that it would be unacceptable to supply contaminated hydrogen to the reactor, all of the real time debris retention, cooling, and fission-product removal (particulate, gaseous, and vapor phase) functions of an open system would be required. Any injected coolant would be required to be removed from the effluent stream (water and nitrogen) or diverted to a secondary loop (hydrogen) that does not include the reactor core. An accumulator system would be required to manage fluid quantities within the loop under the varying temperature and pressure conditions that will occur during test operations and nonoperational (no flow) periods.

Operation of a closed loop system does present several additional problems. Cooling to near liquid hydrogen temperatures would require refrigeration or efficient heat exchangers using liquid hydrogen or liquid helium. Energy loads associated with hydrogen liquefaction have been previously discussed. Hydrogen pumping power requirements for the coolant supply can be quite high if the test reactor does not include an integral turbopump assembly. Additional pumping capacity would be required for any hydrogen used for injection cooling. To satisfy current safety standards, it may be necessary to meet the pumping requirement in a redundant manner.

Another difficulty is that the conversion of ortho-hydrogen to para-hydrogen is a finite rate process. Liquid hydrogen is virtually $100 \%$ para-hydrogen while hydrogen at high temperatures (ambient or above) is a mixture of 75\% ortho-hydrogen and $25 \%$ para-hydrogen by volume. NTP systems use liquid (para-) hydrogen as their primary coolant. As the hydrogen is heated, it is converted to normal (75\% ortho- and $25 \%$ para-) hydrogen. Upon cooling in a closed loop system, it is necessary to convert back to para-hydrogen in order to maintain the proper prototypic fuel and fuel element operating conditions. However, the ortho-para transformation in the absence of a catalyst is a second order reaction (Barron 1985). In the presence of a catalyst, the transformation approaches a first order reaction for the gas phase and a zero order reaction for the liquid phase. Reaction rates in catalyst systems are strongly dependent upon the catalyst used, temperature, and pressure. A closed loop system must be designed with sufficient residence time (and potentially a catalyst) to allow the ortho-para transformation to take place.

A closed loop system both supplies coolant to the reactor (not performed by any of the other ETS concepts discussed) and functions during reactor power operation with no direct path to the environment (like a closed volume system). However, no system is truly "closed". Like a closed volume system, some between power operation waste management operations are required. The system will have to be opened (requiring effluent processing and relief) to remove and replace the test article. The cryogenic adsorption beds (with their associated contaminated noble gases) would also be required to be regenerated.

\section{CONCLUSIONS}

Evaluation of effluent treatment concepts should be performed from a total system approach considering potential environmental impacts, safety, operations, potential future activities, and total cost. To meet present standards, any system designed to treat the effluent of a NTP reactor must have a high degree of reliability and redundancy. Passive systems, such as blowdown rather than pumping, should be employed whenever practical. Exotic materials and concepts should be avoided in the ETS design whenever possible. The test article, not the ETS, should be the focus of the experimental program. Critical system functions (initial cooling, fission-product retention, etc.) should be 
performed in a manner such that a single failure will not lead to loss of the ETS function and fission-product releases to the environment. Steps should be taken to minimize occupational exposure during required in-service maintenance, inspection, and testing. The entire ETS should be expected to become contaminated. Significant residual radioactivity was observed after the operation of NF-1 (Kirk 1973). This was believed to be the result of the decaying xenon leading to deposition of lanthanum on the system surfaces. It may be necessary to perform much of the maintenance and inspection using remote or robotic means.

The ETS support systems (such as coolant storage and handling, or water remova) and posttest processing systems (as for decay heat removal, pebble bed heat rejection, or gaseous and liquid waste processing) can have significant impacts on overall system complexity and cost, which should not be overlooked. Systems that meet specific functional requirements (rather than individual components) should be compared. The potential for future expansion should be considered. Any ETS concept is, to a first approximation, a power limited system. Many of the individual component designs (piping and valving, injectors, heat exchangers, filters and adsorbers, for example) are designed based upon velocity. If it is desired to significantly increase reactor power (and thus flow), it would be necessary to significantly increase the size of the velocity limited components or to use process trains in parallel. A total energy limit also exists for an ETS. This limit is defined by the storage capacity (coolants, heat sinks, closed volume fissionproduct retention, and so on) of the systems. The potential test duration at a given power can be extended by increasing the system storage capacity. This expansion can be accomplished in a more straightforward manner (for example, adding coolant storage for injection or heat exchangers versus incorporating additional pebble bed heat sinks in the process train) for some systems than others.

The need for low ETS operating pressures to support altitude simulation can have a significant impact on system design. It would be necessary to recover sufficient pressure from the high-speed flow to overcome the system backpressure. Since many of the system components will be sized based upon flow velocity, the overall system size can be expected to increase as operating pressure decreases. The potential exists to incorporate a diffuser into the debris retention component design. Injectors or ejectors could be used to lower the system inlet pressure and to cool the effluent stream.

Both the capital and the life cycle costs of system options should be evaluated. Evaluation to date has shown that the use of large complex equipment and systems should be minimized for a limited testing program. For example, when injection cooling is used, a large number of tests are required before the increased capital cost of water removal systems is balanced by the increased operational cost associated with hydrogen injection. The system end of life decontamination and decommissioning costs should also be considered.

\section{Acknowledgments}

This work was performed at Sandia National Laboratories and was partially funded by Phillips Laboratory, Kirtland AFB, New Mexico. Sandia National Laboratories is operated for the U.S. Department of Energy under contract number DE-AC04-76DP00789.

\section{References}

Aerojet-General Corporation (1969) XE-Prime Engine Final Report, Volume I, Engine and Facilities Report, RS-S0510, Aerojet-General Corporation, Nuclear Division, Sacramento, California, December 1969.

Allen, G.C. et al. (1992b) "Ground Test Facilities for Evaluating Nuclear Thermal Propulsion Engines and Fuel Elements," in Proceedings of the 1992 Nuclear Technologies for Space Exploration, Jackson, WY, 16-19 August 1992, pp 514-523.

Baer, M. (1991) Personnel communication to L. R. Shipers, September 1991.

Barron, R. F. (1985) Cryogenic Systems, Oxford University Press, New York.

Bohl, R. J., D. L. Hanson, and F. J. Edeskuty (1990) "Planning for Ground Testing of Nuclear Rocket Engines With Today's Environmental Awareness," AIAA-90-2517. 
Clark, J. S., Marshall, A., Wickenheiser, T. J., Bhatacharryya, S. K., Doherty, M. P., and Warren, J. (1992), "NASA/ DOE/DOD Nuclear Propulsion Technology Planning: Summary of FY 1991 Interagency Panel Results," Proceedings of the 1992 Nuclear Technologies for Space Exploration, American Nuclear Society, Jackson, WY, 16-19 August 1992, Part II, pp 331-340.

Finseth, J. L. (1991) ROVER Nuclear Rocket Engine Program Overview or ROVER Engine Tests Final Report, National Aeronautics and Space Administration, File No. 313-002-91-059, February 1991.

Harmon, C. D., C. A. Ottinger, L. C. Sanchez and L. R. Shipers (1992) "Ground Test Facility for SEI Nuclear Rocket Engines," AIAA 92-3266, AIAA 92-3266AIAA/SAE/ASME/ASEE 28th Joint Propulsion Conference, July 6-8, 1992, Nashville, TN.

INCO Research and Development Center (1980), "Metallurgical Studies of Hydrogen Storage Alloys," BNL-51174, April.

Kirk, W. L. (1973), Nuclear Fumace-1 Test Report Los Alamos Scientific Laboratory, LA-5189-MS, Los Alamos, NM, March 1973.

Koenig D. R. (1986), Experience Gained from the Space Nuclear Rocket Program (ROVER), Los Alamos National Laboratory, LA-10062-H, Los Alamos, NM, May 1986.

Lin, T. and J. S. Watson (1987), "Heat Transfer in Iron-Titanium Hydride Beds," Oak Ridge National Laboratory, ORNL/TM-8982, Oak Ridge,TN, January1987.

McCormack, J. D., R. K.Hilliard and A. K. Postma (1984), Submerged Gravel Scrubber Demonstration Tests; Performance of a Large-Scale Unit, Hanford Engineering Development Laboratory, HEDL-TME-83-12, Richland, WA.

Pope, A. and K. L. Goin (1965), High-Speed Wind Tunnel Testing, John Wiley \& Sons, Inc., New York.

Rightley, M. J. and D. F. Beck (1992), NPR/FCIEXO-FITS Experiment Series Report, Revision 1, Draft for Review, NPRW-SA91-3, Sandia National Laboratories, Albuquerque, NM, May 1992.

Salzano, F. J. (1974), editor, Hydrogen Storage and Production in Utility Systems, First Annual Report, Brookhaven National Laboratory, BNL 19249, Upton, NY.

Timmerhaus, K. D. and T. M. Flynn (1989), Cryogenic Process Engineering, Plenum Press, NY.

Whitbeck, J. F. and T. Olsen (1991), Preliminary Study of Facility Options for Ground Testing of a Nuclear Thermal Propulsion Engine, Idaho National Engineering Laboratory, EGG-NPD-9548, Idaho Falls, ID, June 1991. 